\title{
The Use of Product Placement in Books and E-Books
}

\author{
Lecturer Meda MUCUNDORFEANU, PhD \\ Faculty of Political, Administrative and Communication Sciences, \\ Babeş-Bolyai University, Cluj-Napoca \\ E-mail: mucundorfeanu@fspac.ro
}

\section{Assist. Prof. Julia SZAMBOLICS, PhD}

Faculty of Political, Administrative and Communication Sciences, Babeş-Bolyai University, Cluj-Napoca

E-mail: szambolics@fspac.ro

\begin{abstract}
While the majority of research regarding product placement has been done in the context of film, TV productions, music videos and video games, we know little about this practice and its effects in the field of written text. The aim of the present paper is to gather all the relevant data about product placement used in books and e-books in order to set the grounds for further research on the matter. In the following pages we will provide some examples of texts in which product placement was used and we will present the revealing results of three studies which have been conducted regarding product placements in novels.
\end{abstract}

Keywords: product placement, books, branded books, brand names, implicit memory.

\section{Introduction}

Inserting brands and product names into movie or video contents is a common technique that has been used for years. The trend is now making its way into novels. Using the name of a product in text is not difficult and does not involve great 
expenses. Especially when it comes to e-books, publishers have the ability to add or remove brand names depending on target audiences and other factors. In this context, the audience is wondering whether the brands mentioned, for example in bestsellers, are product placements or if they are just elements used by the authors to make the stories more credible, contemporary and to make the characters more authentic.

Experts and consumers alike are preoccupied with various questions in this regard, such as: Are the authors or other entities paid for mentioning brands in their books, or do they receive other benefits? Do publishers enlist companies to sponsor these branded mentions, as film-makers do in Hollywood? Are there agreements regarding the number of times a brand has to be mentioned?

While the majority of research regarding product placement has been done in the context of film, TV productions, music videos and video games, we know little about this practice and its effects in the field of written text. This fact is surprising, because the practice of including product names in books is becoming increasingly popular. In the following pages we will provide some examples of texts in which product placement was used. We will present the results of three studies regarding product placements in novels. The first one testing the so called "mere exposure effect" and containing five experiments, regarding the effectiveness of using product placements of known and unknown brands in novels. The second one is focusing on the implicit memory after reading a text that contained brand placement. The third one is a so called test of the "generation effect", focusing on brand recall after brand names have been fragmented in novels and answers the question whether the effectiveness of brand placements in text will be enhanced if they are incomplete (letters are being left out).

\section{Theoretical framework. The Exposure to Product Placement in Text}

Studied concentrated so far on the impact of certain variables (such as testimonials from celebrities, audible references, etc.) on the memorability of product placements in movies or during television programs, but very few have analyzed the impact of brand placement in written text.

Benjamin C. Storm and Eve Stoller published a study where they presented five experiments they conducted regarding the consequences of the exposure to product placement in text (Storm, Stoller, 2014). Their analysis starts from the premises of the "mere exposure effect" (Zajonc, 1968, 1980), which shows that the more someone is exposed to a stimulus, the more they like that stimulus.

All of the five experiments required different participants to read three novels, which contained different amounts of product placements of familiar and unfamiliar goods: in each experiment the number of times a product was mentioned was different. The study tried to show the likelihood participants would purchase 
certain goods after reading the novels. Some of the research questions regarded brand judgments after the exposure to product placement, the optimal degree of product placement, the persistence of product placement over time, the degree to which consumers can protect themselves from this advertising technique, but also regarding the consequences of product placement correlated to the brand familiarity. We will present some of the most notable answers to these questions.

In a couple of the five experiments, participants were handed over an article expressing a negative view of product placement before reading the short novels. The fascinating result in this respect was that "the effect of exposure was nearly identical in the two conditions, suggesting that making consumers aware of product placement - and even explicitly telling them that they should consider resisting its influence - does not necessarily limit its effectiveness." (Storm, Stoller, 2014) The effectiveness of the advertising technique used was not diminished by the article, which explicitly warned readers about the power product placement had over them.

Another revealing fact is that the effects of product placement persist nearly a week after exposure, possibly due to the fact that after reading a book, the reader actively thinks about the plot for several days.

One useful result for advertisers everywhere is the result of the second experiment, which dealt with the fact that even a small number of exposures carry the potential to have a persisting impact on the readers. The second useful result for advertisers is that the exposure to unfamiliar brands was more effective than the exposure to familiar brands, maybe due to the prior experience and knowledge of the readers of the latter.

The "mere exposure effect" has also been validated in this study. The general assumption is that readers may feel so irritated when a text is abundant with brand names that their opinion of the placed goods may begin to decline. In one of the experiments, almost $7 \%$ of text consisted of brand names, but the readers surprisingly did not react negatively to that exposure, consequently product placement can also be effective when participants are facing a striking number of exposures. It would be interesting to conduct further research to see if readers (knowing that they do not disconsider brands which have been used in texts such as novels) would disconsider the quality of the novel itself and the intention of the author.

Another study is part of an interesting $\mathrm{PhD}$ thesis written by Isabel Manzano (2010), which focuses on implicit memory and tried to determine if participants displayed implicit memory for the brands mentioned in a story, because most studies focused rather on studying the explicit memory of ads, thus neglecting the implicit memory.

The author of the PhD thesis (Manzano, 2010) conducted three experiments and gained revealing results. One of them was that presenting participants with 
brands in a narrative, can lead them to remember those brands better. Once again it is confirmed that product placement in books is effective, finding which is very useful for advertisers whose goal is often to make their product more memorable, because consumers spend only five seconds when making shopping decisions and participants in this experiment were forced to make their decisions under a strict time constraint.

In the third experiment participants were asked to create a shopping list scenario. They were given a product category and were given a limited amount of time (four seconds per products) to think of products they would include in their shopping list, after reading a novel containing product placements. One of the predictions was that prominently placed brands should be chosen more often/remembered better than subtle brand placements. But this prediction proved to be wrong. Certainly, participants included in their shopping lists more names of products mentioned in the novel, regardless if they were prominent or subtle brand placements. The conclusion for advertisers is a simple one, they simply need to mention the brand without any mention of its attributes and it is almost certain that readers will remember them. (Manzano, 2010)

The third study (Brennan, 2008) uses as a starting point the findings of experiments conducted in the field of cognitive psychology regarding the memorability of fragmented words versus complete words. The so called "generation effect" occurs when subjects are given cues, similar to crosswords, for solving several problems, rather than complete information, and are then submitted to a memory test based on those problems.

This particular study focuses on brand recall, after brand names were fragmented in novels and answers the question of whether the effectiveness of brand placements in text will be enhanced if the brand names are incomplete, i.e. if letters are left out. The author created five levels of fragmentation, the first one consisting of brand names which are complete, the middle level being called mild fragmentation (1-25\% letters missing) and the last one consisting of brand names which have been altered very severely (76-100\% letters missing). Every experimental group received a short novel containing at a certain point brand names with a different degree of fragmentation. All these brand names were included in the plot as shopping lists and the missing letters were justified through various incidents, for example in one instance, the character supposedly spilled coffee over the shopping list, etc.

The most interesting results were the following: brand names which were slightly fragmented at the end and offered the reader a minor decoding challenge were recalled more often than the brand names which were not fragmented at all or which were severely fragmented. The same result was achieved regarding mild fragmentation in the middle of the brand names as opposed to complete brand 
names or severely fragmented words. The general conclusion was that "An author who includes a reference to a well-known brand in a novel can enhance recall for the named brand by omitting a small portion of the brand name." (Brennan, 2008) The novelty of this study lies in the fact that a generation effect may be obtained when subjects are exposed to fragmented words which are not isolated, but are part of surrounding text and the task is not explicit for the subjects, that is to complete the missing words. These finding are very interesting not only for product placement in novels, but especially for advertisers who use or intend to use product displacements, since now we have scientific evidence of the fact that giving the audience cues, rather than complete names, leads to a better recall of those brands.

\section{Examples Product Placements used in Books with Commercial Purposes}

An initial form of product placement in books was for cigarettes. In the 1980's on the back pages of novels, readers would often find cigarette advertisements. (Du, Zhiwen, 2013). However, in this case the plot was separate from the commercial part, the ads were obvious.

A well-known example in this regard is the novel entitled "The Bulgari Connection" where the Italian jewelry company paid the well-known British author, Fey Weldon, an undisclosed amount of money to write the novel in which to promote their brand. (Motoko, Rich, 2006). This is considered the first ever commissioned product placement deal in publishing history and it goes even further, for the launch of the book, the author wore over $\$ 1.5$ million worth of jewelry. ${ }^{1}$

The initiative to insert the names of certain products in a book was not successful in the first example. The mystery novel for young girls entitled "Cathy's Book" published by Sean Stewart and Jordan Weisman in 2006 contained characters wearing specific makeup lines made by "Cover Girl". After the publisher "Running Press" revealed that the authors had agreed to mention those makeup lines in their text in exchange for promotional ads for the book, placed on websites aimed at adolescent girls, the novel was harshly criticized, among others, by "The Los Angeles Times" and "The New York Times" (Motoko, 2008). After those bad reviews, all the references of the makeup-line "Cover Girl" were removed for the paperback version, in order to avoid bad publicity. So the advertising initiative backfired.

Of course, there are also successful examples of placed product names in books. For example, experts have wondered about whether the brands mentioned in popular bestsellers for adolescents, such as "Gossip Girl", "A-List" and "Clique" are product placements. "The books have an average of one brand name

1 http://www.mhpbooks.com/a-short-history-of-branded-books-and-product-placement-inliterature/ (16.09.2016) 
per page, including mentions of "Juicy Couture", "Armani" and "Viagra", according to a study by Naomi Johnson, a lecturer at Longwood University" (Lanzendorfer, 2008). Now we know that a division of a marketing company creates the concepts and plots for these books, and after they hire writers to write them, they give the manuscripts to publishers. According to the company, they do not accept payments for the product placements, but services, such as cross-marketing campaigns (Lanzendorfer, 2008).

The third example is about the HarperCollins children book series, for 8- to 12-year-old girls, called "Mackenzie Blue" in which product placement was part of the plan from the beginning. The chief executive of a marketing group was responsible for talking to the companies mentioned in the books and proposing them to sponsor the series. According to the marketing specialist, the authors would not change a brand in the book if a company wanted to and that initial brand were a part of the identity of a character; nonetheless they would use the new brand for another character, if it were suitable (Motoko, 2008).

All the examples mentioned above are aimed at children or at teenagers, who are very sensitive and suggestible target groups, but let us not forget that advertising and product placements are totally embedded in the TV shows, movies, music videos and video games used by them.

Another area where we are used to seeing advertisements are magazines and comic books. A new trend is to include the brand names not only between stories and articles, but also in the plot of comic books and to integrate them into the story. Comic books are particularly attractive to advertisers, because their target group consists of 18- to 34-year-old male consumers, as the average comic book reader is a 28-year-old man who spends 1,300 to 1,500 dollars a year on this hobby (Stringer, 2006). In the six-issue-series "Rush City", the brand is not only mentioned in the story, but it is the only thing owned by the main character, who became an action hero after losing his family and his job. The product was General Motors' new "Pontiac Solstice GXP", which was launched in the comic book (Stringer, 2006). Undoubtedly this is an example of classic product placement, the launch of a new product placed in media content, which is a technique consumers are used to seeing in blockbuster movies.

The American author Stephen King is also known under the name of "the king of product placement", because he uses plenty of brand names in his books in order to make his characters authentic. The problem here is that those brands are well-known by the American public, but the European public, for example, does not know them and they interrupt the reading process when the reader cannot understand what the character is eating, where he is going, what he is carrying, preventing the reader from associating his or her experience to that of the character. 


\section{Examples of Product Placements used in Books without any Commercial Purposes}

There are few examples of product placements used in novels, where we can absolutely be sure that they do not have any commercial purposes.

One example stems from the well-known French writer Frédéric Beigbeder. In his famous trilogy he uses many brand names, not for advertising purposes, but as a means of describing the world and the characters he is presenting in his novels. Being an advertising expert himself, a former copywriter, he surely knows about the consequences and the effects of using such techniques. He shocked the advertising world with his satirical novel "99 francs", which was retitled "14.99 euro" after the introduction of euro, because in the partly autobiographical story, he presents Octave, a copywriter, by using in the first sentence, but also in the rest of the book, lots of enumerations of brands, with no commercial purpose whatsoever. His intention was to describe the young men as good as possible, because we are partially defined by the brands we use. ${ }^{2}$

Another example of extreme brand dropping is the controversial novel "American Psycho" by Bret Easton Ellis published in 1991. The novel includes countless brands, names of bars, clubs, designer clothes and accessories, both real and fictional, because the protagonist Patrick Bateman is extremely style-conscious. The brands were not mentioned with a commercial purpose either, but rather "for describing a morally flat world in which clothes have more value than skin. ${ }^{3 \prime}$

\section{Product Placement in E-books}

When it comes to e-books, there are advertisers who imagine even more possibilities when it comes to this type of texts: for example, if a cosmetic company sponsored an e-book, the characters would have to use the company's products. Nothing new in this approach, but the scenario goes even further: in the first, let's say, fifty thousand copies, the characters would wear those products, but if another company from the same field offered more money, then, in the next fifty thousand copies, the characters would use the competitors' products. So, depending on when readers buy the e-book, they would read different things, as far as the cosmetic preferences of the characters are concerned.

A novelty in the field of product placement is the e-book "Find Me, I'm Yours" by Hillary Carlip, which is actually a series of websites and TV shows, all sponsored by various companies. This book was promoted also through cards, which were handed to potential customers, who could scan the QR Codes on them and then download the e-book. Everything goes one step further. Because the cards

2 http://brandsandfilms.com/2010/09/why-its-important-to-have-brands-in-books/ (14.03.15)

3 http://brandsandfilms.com/2010/09/why-its-important-to-have-brands-in-books/ (14.03.15) 
contain individualized codes, they can render very important consumer insights, such as: how much time the readers spend with the book, whether they reread certain paragraphs, all valuable information for advertisers. The creators even built 33 websites and included them into the story line. This book was written in three years and the investment was about $\$ 400,000$. It was a collaboration between the author and Maxine Lapiduss, a TV producer and writer for shows such as "Roseanne", "Ellen" and "Dharma and Greg". Together they have created an entertainment studio named "Storyverse Studios" where they work together with 35 writers and a social media team. (Alter, 2014)

\section{General Discussion}

According to Brennan and his colleagues, memory largely depends on the context and this should also apply to the placement of products. The context of the placement is the key factor, so the context should be prominent (Brennan, 1999). Techniques such as connecting the name of a product with the plot of a story or presenting action in which the lead character uses a product, should lead to consumers remembering that product.

Consequently, even unfamiliar brands, when placed into a certain context should be easily remembered, which is important, because during the buying process, people tend to buy products they already know or have heard of, from different sources.

"Research on how we make metacognitive judgments suggest that consumers may fail to realize the connection between exposure to product placement and the enhanced preference they subjectively feel for a placed product, thus leading them to attribute their enhanced preference to their views of the product instead of their exposure to product placement." (Storm, Stoller, 2014)

Another aspect is the ethical factor when it comes to letting advertising invade the intimate relation a reader creates with the characters when reading a book. Unlike other exposures to other media - such as TV series, movies, video games, music videos, radio shows - reading a book is a solitary act. A book is the single medium which persons use only individually, which is not shared during the process, so the grade of intimacy and isolation while using this medium is greater. Consequently, the individual is more open, more susceptible to influential factors, while being in the comfort of his or her own experience. In different circumstances, on the street, on TV, in video games, consumers can try to avoid the advertisements, to look away or to do something else while the ad is playing or while driving through a street, but when ads are placed in books, readers cannot skip the parts with the brand names, on the one hand because they do not know when the advertising part is beginning, as it is not highlighted in bright colors or written in large fonts, and on the other hand, because it is impossible to fully understand the 
message of the plot and it would be unpleasant to try and avoid reading text passages which could contain brands. This is the reason why, from the advertisers' point of view, the use of product placement could be highly effective, because they have the undivided attention of the reader, as books cannot be read while doing something else or talking to someone, in comparison to other media use. Therefore, novel writers should be aware of the power of the placed advertisements, especially in text, and think twice before making an agreement with a brand, to prevent a situation where that power becomes greater than that of the plot, the tone, the atmosphere and the intention behind the story.

Product Placement is in the legal grey area between the forbidden subliminal advertising and the integration of economic goods in the media program (MüllerRüster, 2010). Product placement can be direct or indirect (La Ferle, 2006), it is used in new areas and in new forms as well. Two of these new forms are called "reverse product placement" and "product displacement" and we will describe them briefly.

\section{Reverse Product Placement}

While in classic product placement first we have a brand in real life, and then we see it in the media content, when it comes to reverse product placement, the strategy is the other way around: here we have the product first in the media content, for example in a movie or in a series, with no intention whatsoever to sell it, and then, after that movie becomes popular it can happen that a company decides to create a product with the exact same name and package which were used in the movie scenes. For the manufacturing company, this strategy can be very successful, because the movie and ,implicitly the product, already have millions of fans who know the product and do not need a lot of persuasion to buy it.

Some examples of reverse product placement are: "Bubba Gump Shrimp Company", the chain of restaurants from "Forrest Gump", the "Duff" beer from "The Simpsons" ${ }^{4}$, or the "MacLaren's Pub" from the series "How I Met your Mother".

\section{Product Displacement}

Another form of product placement is product displacement. This happens in media contents such as movies, series or music videos, when the public sees a brand name or logo, which is deliberately and strategically covered up, but in such a way, that the audience can still recognize the product. The difference between this type of advertising strategy and classic product placement is that the former is more subtle, it makes the audience think, it gets the public involved in

4 http://www.brandchannel.com/home/post/2011/12/02/At-the-Movies-Greatest-ReverseProduct-Placements-Of-All-Time.aspx (06.12.2014) 
the advertising process, because they have to fill in the blanks and this technique does not look like advertising at all. Some logos are slightly covered or modified and everyone can recognize them, in which case it can be paid advertising. There are also cases in which the logos are fully erased or covered up and the product cannot be recognized - in these cases the producers wanted to avoid doing advertising for certain goods for free. The lack of facts and studies in this area, among others, leaves us just with suppositions.

The blogger Gladys Santiago has developed a classification of product displacement: ${ }^{5}$

We can talk about "fictionalized" product displacement, where characteristics of existing companies or products are placed in a movie, and several elements are altered in such a way that we can still recognize the product (not only the name or the logo is altered, but also the colors, the shapes). "Fictionalized brands differ in that they reference actual companies. For example, the characters in Scrubs frequently gather at a coffee shop called Coffee Bucks. The name, decor, menu and logo of Coffee Bucks are obviously modeled after the Starbucks franchise. Fictionalized product displacements are created by referencing recognizable characteristics of real brands." ${ }^{6}$

The "unbranded" product displacement has two forms: "digital alteration", where the logo has been modified, replaced, pixilated or erased in post-production through a computer program and "physically obscured", when the name or the logo of a product is covered up entirely or partially by another object, or by the hand of one of the actors, for example, but in such a way that the brand is still recognizable. This technique is widespread and especially in TV series one can encounter several examples where brands are placed in this manner.

\section{Conclusion}

Fact is, as long as consumers will try to avoid advertising, advertisers will try to find new creative ways to find these consumers.

Until researchers publish more studies on the impact and consequences of ads placed in books, the placement of product names in text could be considered an issue that has to be seen from several perspectives, from the perspective of the production companies, the advertisers, the readers and the writers. There are pros and cons for each group, but the key factor, the decision makers in this process should be the writers. There is a possibility that when this trend continues, adver-

5 https://gladyssantiago.wordpress.com/2009/04/16/product-displacements-explained-part-1/ (06.12.2014)

6 https://gladyssantiago.wordpress.com/2009/04/16/product-displacements-explained-part-1/ (06.12.2014) 
tising could start dictating the content of novels and writers could find themselves in the situation of either incorporating brand names into their stories or losing their book deals. But they also could turn this practice to the advantage of each group involved, they could accept the placement of products to an extent where it does not alter the content of their writing, where the number of times that a brand is mentioned does not overwhelm or irritate the readers, and in this manner the characters and scenery in books could be relatable and many talented part-time writers could afford to become full-time writers and therefore readers could enjoy more of their writing.

Trends like these are inevitable, new and different forms of advertising will be used in places that were once considered sacred, such as literature, but the advertisers have to take into account different strategic aspects, in order for the ads to be efficient and for the authors not to lose credibility: the products should be perfectly suitable with the target group of the book, but also the frequency with which the products are mentioned should be suitable for the features of the target group, such as age, gender, social status or education. For certain readers, repetition would be a problem, while for others it would be pleasant, or while some readers enjoy getting closer to new cultures, also through the brands that are used in books, for others, the unfamiliar products could prevent them from living the full experience a book can offer.

\section{References}

1. Alter, A. (2014). E-Book Mingles Love and Product Placement, New York Times. Retrieved from: http://www.nytimes.com/2014/11/03/business/media/e-book-mingles-love-and-product-placement.html.

2. Brennan, I., Dubas, K.M., \& Babin, L. A. (1999). The influence of product- placement type \& exposure time on product-placement recognition. International Journal of Advertising: 18 (3).

3. Brennan, I. (2008). Brand placement in novels. A test of the generation effect. International Journal of Advertising: 27 (4), 495-509.

4. Du, Z. (2013). The relationships between product placement in recreational TV programmes and mass consumption, MA Thesis, Uppsala University, Sweden. Retrieved from: http://www.diva-portal.se/smash/get/diva2:659637/FULLTEXT01. pdf.

5. La Ferle, C., Edwards, M. (2006). Product Placement: How Brands appear on Television. Journal of Advertising: Vol. 35, Nr. 4, Oxfordshire.

6. Lanzendorfer, J. (2008). Is more Product Placement in Young-Adult Books Inevitable?, The Writer: Sept. 2008.

7. Manzano, I. (2010). Product Placement: Implicit Memory and Choice for Brands Placed in a Novel, Ph.D. Thesis, A\&M University, Texas. Retrieved from: http:// 
repository.tamu.edu/bitstream/handle/1969.1/ETD-TAMU-2010-08-8403/MANZA NO-DISSERTATION.pdf?sequence $=3$.

8. Müller-Rüster, J. (2010). Product Placement im Fernsehen, Mohr Siebeck, Tübingen.

9. Parreno, J.M., Mafe, R.C., Scribner, L. (2015). Engaging Consumers through Branded Entertainment and Convergent Media, ICI Global, USA.

10. Rich, M. (2008). In Books for Young, two Views on Product Placement. New York Times. Retrieved from: http://search.proquest.com/docview/433778826?accountid= 8013.

11. Rich, M. (2006): Product Placement Deals make Leap from Film to Books. Retrieved from: http://www.nytimes.com/2006/06/12/business/media/12book.html?_r=0.

12. Storm, C.B., Stoller, E. (2014). Exposure to Product Placement in Text Can Influence Consumer Judgment. Applied Cognitive Psychology.

13. Stringer, K. (2006). Comic books draw in ads: Product placement expands to new territory. Tribune Business News: June 19. Retrieved from: http://search.proquest. com/docview/465272311? accountid=8013.

14. Zajonc, R.B. (1968). Attitudinal effects of mere exposure. Journal of Personality and Social Psychology Monograph.

15. Zajonc, R.B. (1980). Feeling and thinking: Preferences need no inference, American Psychologist.

\section{Online sources:}

16. www.brandchannel.com

17. www.brandsandfilms.com

18. www.gladyssantiago.wordpress.com

19. www.mhpbooks.com 